\title{
An Analysis of the Impact of Fiscal Subsidies on Farmers' Demand for Agricultural Insurance
}

\author{
Xiaojun Pan ${ }^{1,2}$, Chengyi $\mathrm{Pu}^{3}$, Mingyan Yang ${ }^{2}$ \\ ${ }^{1}$ Academy of Disaster Reduction and Emergency Management, Faculty of Geographical Science, \\ Beijing Normal University, Beijing 100875, China \\ ${ }^{2}$ School of Economics, Southwest Minzu University, Chengdu 610041, China \\ ${ }^{3}$ School of Insurance, Central University of Finance and Economics, Beijing 100081, China \\ 1002343190@qq.com \\ 财政补贴、农业保险与农户增收 \\ 潘小军 ${ }^{1,2}$, 蒲成毅 ${ }^{3}$, 杨名艳 ${ }^{2}$ \\ 1. 北京师范大学, 减灾与应急管理研究院, 北京, 100875, 中国 \\ 2. 西南民族大学, 经济学院, 成都, 610041, 中国 \\ 3. 中央财经大学, 保险学院, 北京,100081, 中国 \\ 1002343190@qq.com
}

\begin{abstract}
This paper analyzes the current situation of agricultural insurance and subsidies in Sichuan Province from 1998 to 2018, and finds that financial premium subsidies, disaster-stricken areas, per capita disposable income, and claims ratios have certain correlations with agricultural insurance. Among them, financial subsidies increase farmers' demand for agricultural insurance by reducing farmers' participation in agricultural insurance, and effectively reduce the risk of agricultural production. However, the incentive effect on the demand of farmers has not been expected to have a large effect, such as low compensation rate, low coverage rate, market violations, adverse selection, and single subsidy mechanism. It was also found that in the early 21 st century, Sichuan Province, as a large agricultural province in the southwestern region, was in a state of very depressed agricultural insurance. Under the background of the national policy to promote the development of agricultural insurance, it was also the first batch of the 2007 financial premium subsidy policy. One of the pilot units, its agricultural insurance development has achieved remarkable results and ranks among the top in the country. Therefore, the government should continue to improve the subsidy policy, innovate the subsidy mechanism for agricultural insurance, better understand the needs of farmers, better play its functions to support agricultural development, ensure farmers' incomes, and promote rural revitalization.
\end{abstract}

Keywords: financial subsidies; agricultural insurance; farmers' income

摘要一本文通过 1998-2018 年四川省农业保险和补贴的现 状进行分析, 发现财政保费补贴、受灾面积、人均可支配收 入、赔付率与农业保险需具有一定的相关性。其中, 财政补 贴通过减少农民参与农业保险的投保费用提高农民对农业保 险的需求，有效降低了农业生产的风险。但对农户需求的激 励效果并没有预期的效果大，存在补偿率低、覆盖率低，市 场违规、逆向选择，补贴机制单一等问题。四川省作为西南
地区的农业大省，政府应继续完善补贴政策，创新农业保险 的补贴机制, 深入了解农民的需求, 更好发挥其职能扶持农 业发展, 保障农户增加收入, 推动乡村振兴。

关键词：财政补贴; 农业保险; 农户增收

\section{I. 引言}

农业保险具有分散农业风险损失，规避和转移农业 风险，防灾减损、经济补偿、弥补农民损失，稳定农民 收入，促进农业良性发展。我国农业保险的发展经历了 二十世纪三十年代的萌芽期；1949-1958 年短暂的繁荣 期; 1982-2003 年的恢复期; 2003 年后的高速发展期。 2003 年，中央一号文件第一次提出建立政策性农业保险 制度，随后几年的 7 个涉农一号文件中都提到了要逐渐 加大对农业保险的财政支持力度，对购买农业保险的农 户提供补贴, 提高其购买农业保险的积极性。2010 年中 共中央、国务院关于加大统筹城乡发展力度, 进一步夯 实农业农村发展基础的若干意见中提出要加大农业保险 保费的补贴力度、扩大政策性农业保险的覆盖种类和区 域范围，鼓励发展特色农业保险。

四川是农业大省, 特殊的地理位置和气候条件使其 传统农业发达，物产丰富，品种繁多; 但传统农业是一 个弱质型产业, 易遭受自然灾害的侵袭, 四川自然灾害 种类多, 灾害并发和频发, 农业遭受自然灾害的损失重 ，农民常因灾致贫和返贫。从 2007 年四川省的政策性农 业保险试点以来, 农业保险发展迅猛, 农业保险保费收 入由 2007 年的 75389.2 万元增加到 2018 年的 375852.17 万元，增加了约 4 倍之多; 农业保险的赔付也由 2007 年 的 46722.5 万元增加到 2018 年的 262382.4 万元，赔付金 额为 2007 年的 5.6 倍, 起到了很好的为农业保驾护航的 作用。 


\section{II. 国内外文献综述}

国外对财政补贴对农业保险之间关系的研究有, Wright 和 Hewitt[1]（2006）, Justin[2]（2010）, 研究 得出财政补贴可以激励农业保险的潜在需求者, 将潜在 的保险需求转变为有效的保险需求; Russell[3]（2014） 政府对棉花种植的补贴法案有效地增加了农户对农业保 险的需求；Donoghue[4]（2014）美国政府对农业保险 的补贴助于已经参与农业保险的农民继续增加对更多作 物的农业保险投保。Collins[5]（2006）政府的财政补贴 可改善市场失灵的状况。Tronstad[6]（2010）指出, 政府 在农业保险补贴不仅能增加农户对农业保险的参保意 愿, 还能激励其增加种植面积。国外的学者的研究得出 政府财政补贴对农业保险需求有正向激励作用, 特别在 农业保险发展相对于落后的地区, 可促进该区域农业保 险市场的发展。

国内对政策性的农业保险的作用主要从：政府的农 业保险补贴对行为主体农民的冲击作用、对保险机构的 激励作用和补贴的效率角度进行研究。其中对行为主体 农民的冲击的研究有: 于雪妍 [7] (2017) 研究了河南省 的政策性农业保险, 得出财政补贴对对农户的农业保险 需求有正向激励。沈昱池等 [8]（2014）、刘晓丹 [9] （2018），袁连升等 [10]（2014）、刘蔚、孙蓉 [11] （2016）等的研究发现, 农业保险补贴不仅对农民购买 农业保险的行为产生影响还对农业生产结构也有影 响, 。王根芳[12]（2013）认为农业保险是私人物品, 具有排他性和非竞争性, 农民从规避自身的风险购买。 姜岩等[13]（2012）研究了农户的参保行为认为农业保 险费率高于预期收益是影响农户投保决策的重要因素。 对保险机构影响的研究用: 王洪波[14] (2016) 认为财 政保费补贴既可以刺激农户潜在的保险需求也可以刺激 保险公司的农业保险的供给; 黄正军[15]（2018）发现 差异化的保费补贴政策是一种更有效的机制。夏益国等 [16]（2015）认为农业保险存在市场失灵, 财政补贴可 减少赔付率, 改善农业保险市场的失灵状况。刘桦灿等 [17]（2018）得出财政补贴减少保费收入的波动, 使保 费收入与赔款支出间有长期稳定关系。邓志英等 [18]

（2018）研究湖南省政策性农业保险的补贴效率得出补 贴对保费收入及人均保费都有影响。刘璐等 [19]

（2016）认为预防性政策对农业保险的发展具有正效 应, 补偿性政策对农业保险作用有限。

财政补贴的效率研究：李琴英[20]（2014）、胡义云[21]

（2016）分析农民参保率依旧不高的原因, 应优化补贴 方案, 更好发挥其作用; 方伶俐 [22]（2008）提出完善 农业保险补贴的配套方案, 创新补贴政策和模式。朱甜 甜[23]（2014）对财政对农业保险的补贴绩效进行研究 要根据地区差异、农户差异进行不同程度的补贴。

农业保险是为从事农、林、牧、渔业的农民，当农 业活动因为疫情、疾病、自然灾害等导致的损失, 提供 补偿的保障机制。由于农业自然风险具有系统性、多样 性和分散性; 同时还面临着市场风险、社会风险、技术 风险等多种风险的参差交错。导致了农业风险的弱可保 性和农业保险的高费率, 如果用商业性经营模式则会出 现农业保险市场的 “需求不足” 和 “供给短缺” 并存的 失灵态势。同时农业保险产品是有正外部性的准公共产
品, 市场不能自发的调节其需求和供给, 故农业保险市 场存在着市场失灵现象, 故需要通过政府的政策扶持使 农业保险的供给与需求达到均衡。本文从理论上与实证 上分析财政补贴与农户农业保险需求关系。

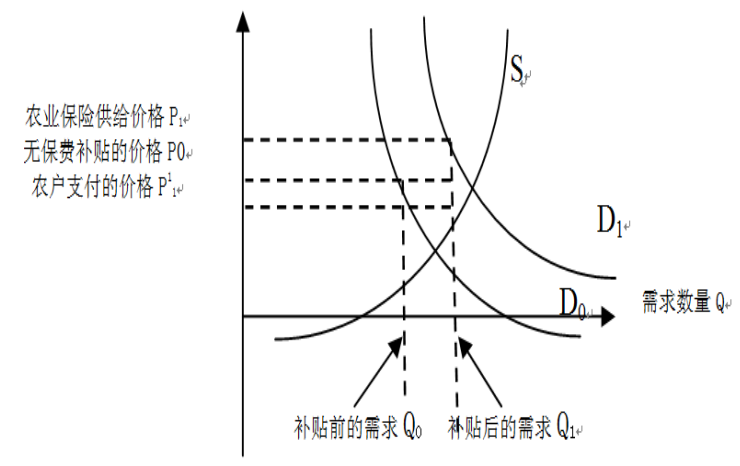

图 1 政府对农业保险购买者补贴的供求的影响。

\section{III. 财政补贴与农户农业保险需求的分析}

从图 1 中可以看出, 当购买农业保险没有补贴时, 农户的需求曲线为 $\mathrm{D} 0$, 市农业保险的需求量为 $\mathrm{Q} 0$, 市场的 均衡价格为 $\mathrm{P} 0$, 即农户支付的价格为 $\mathrm{P} 0$; 当政策性的 农业保险实施后, 农户的保险的需求量增加为 $\mathrm{Q} 1$, 需 求曲线由 $\mathrm{D} 0$ 移动到 $\mathrm{D} 1$, 在市场供给不变的情况下, 市 场的均衡价格为 P1, 但由于有对农户的补贴, 他们实际 承担的保险费用下降为 P11。政府补贴对农业保险需求 曲线、农户支付的实际价格水平、保险公司的有效价格 都有影响, 农民承担的保费就会降低, 增加了农民购买 意愿, 保险需求增加。

\section{IV. 四川省农业保险发展概况与农业保险补贴现状}

\section{A. 四川省农业保险发展概况}

四川是农业大省, 是自然灾害高发区, 每年都会有 自然灾害发生造成农业损失，产量波动极大，农民造成 的经济损失。

为弥补遭受自然灾害给农业造成的损失, 保障农民 收入, 四川省 2004 年开始推动政策性农业保险的实施, 当年的赔付率为 $137 \%$ 。2007 年正式实施政策性的农业 保险, 保费收入由 2006 年的 9174 万元增长到 75389 万 元, 为 2006 年的 8.2 倍, 承保的险种也增加到几十个, 覆盖范围扩大到全省大部分地区, 参保农户数量规模增 大； 2007 年后四川农业保险稳步增长，2018 年农业保费 收入 37 亿元, 是 2007 年的 5 倍, 规模已位于全国前 列, 说明财政补贴对于改变农户农业保险需求影响大, 农业和农村的繁荣发展离不开政策性农业保险的支持。 四川省推进普惠金融发展规划（2016-2020 年）预计到 2020 年, 农业保险乡镇覆盖率 $99.9 \%$ 、村级覆盖率 95\%，参保农户覆盖率 95\%以上。

\section{B. 农业保险补贴的现状}

对农业保险的财政补贴采取中央财政局拨款与地方 财政相结合，从 2007 年的 40682 万元增加到 2018 年的 176834 万元, 为 2007 年的 4.3 倍多。农业保险补贴险 种、金额、范围、结构不断调整; 补贴品种方面, 增加 
了有区域特色的青稞、牦牛、藏羚羊、马铃薯等的补 贴, 鼓励特色农产品的发展, 对烤烟和高粱等进行奖 补, 提高政府补贴的比例, 基本上覆盖了主要的农牧产 品。补贴结构方面: 调整省市县间比例分摊的补贴比 例, 加大省市一级的补贴比例。补贴金额方面：调高了 玉米、油菜、水稻等补贴金额; 加大对森林保险的补 贴, 取消了起赔点, 绝对免赔额从 $10 \%$ 降低到 $5 \%$; 对 育肥猪、奶牛等的补贴增加同时降低农户的缴费标准。 补贴范围方面: 由最初的几个试点区域增至全省所有的 地区。保险产品不断创新：推出育繁肥猪价格指数保险 等。

\section{V. 农险财政补贴与农户农险需求的实证分析}

A. 变量的选取

农业保险需求影响因素虽然多, 本文仅从农户角 度, 讨论其影响因素。故选取变量: 保费收入 ( $\mathrm{Y}$ ) 保 费的财政补贴（X1）、成灾面积（X2）、农村居民人均 可支配收入（）X3）、农业保险赔付率（X4）。

表 1 四川农业风险、农业保险、财政补贴与农户收入 （1998-2018 年）

表1 四川农业风险、农业保险、财政补贴与农收入(1998-2018年)

\begin{tabular}{|c|c|c|c|c|c|}
\hline 年份 & $\begin{array}{c}\text { 保费攸入 } 1 \\
\text { (万五) }\end{array}$ & 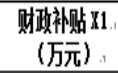 & $\begin{array}{c}\text { 成灾面和 X2 } \\
\text { (万公顾) }\end{array}$ & $\begin{array}{c}\text { 农民可支配收入 } \\
\text { X3 (元) }\end{array}$ & $\begin{array}{c}\text { 赔付率 X4 } \\
(8)\end{array}$ \\
\hline 1998. & 339.0. & 0.0. & 172.7. & 1789 & 41.59. \\
\hline 1999. & 78.0. & 0.0. & 163.3. & 1843.1 & 82. 05. \\
\hline 2000 & 33.0. & 0.0 & 251.3. & 1903. & 145.45 \\
\hline 2001. & 79.0. & 0.0. & 299.9. & 1986. & 69.62. \\
\hline 2002. & 93.0. & 0.0 & 135.2 & 2107. & 104.30 \\
\hline 2003. & 93.0. & 0.0. & 203.2. & 2229 & 103.23. \\
\hline 2004 & 161.0. & 0.0. & 22.9 & 2580.1 & 137.27. \\
\hline 2005. & 924.0. & 0.0 .1 & 119.8. & 2802 & 90.12 \\
\hline 2006. & 9174.0. & 0.0. & 21.6. & 3002 & 80.73. \\
\hline 2007. & 75369.2. & 40628. & 22.1 & 3546 & 61.98. \\
\hline 2008. & 127591.3. & 59602. & 6.7. & 4121. & 60.33. \\
\hline 2009 & 113628.2 & 50670. & 46.9 & 4462. & 69.22. \\
\hline 2010. & 106818.9 & 54802. & 85.1. & 5086. & 78.00. \\
\hline 2011. & 136048. 7. & 56486. & 112.1. & 6128. & 53.06. \\
\hline 2012. & 159613.7. & 89219 & 119.3. & 7001 & 62. 62. \\
\hline 2013. & 174702.2 & 198349 & 125.8. & 7895 & 74.37. \\
\hline 2014 & 201702.3. & 143893. & 48.4. & 9348. & 65.43. \\
\hline 2015 & 236813.5 & 173323 & 22.2. & 10247. & 58.46. \\
\hline 2016 & 264054.4 & 131513 & 25.2. & 11203 & 58. 95. \\
\hline 2017. & 314066.0. & 141571. & 26.4. & 12227. & 63.65. \\
\hline 2018 & 375852.2 & 176834 & 23.8. & 14617. & 69.81. \\
\hline
\end{tabular}

数据来源：四川省统计年鉴

\section{B. 模型的构建}

影响农户农业保险需求的主要因素有, X1 表示财政 保费补贴, X2 表示成灾面积, X3 表示农村居民人均可 支配收入, X4 表示赔付率, 以 $\mathrm{Y}$ 表示保费收入, 可以 构建以下回归方程: 为检验农业保险财政保费补贴及其 对保费收入的影响情况。

利用 EViews 软件得出如下所示的回归方程:

$\mathrm{Y}=40186.059204+1.027722 * \mathrm{X} 1-100.799527 * \mathrm{X} 2$ $+26.222311 * \mathrm{X} 3-932.230733 * \mathrm{X} 4$
(66128. 72)
(0. 227787)

(183. 8024) $\mathrm{t}=(0.632383) \quad(2.121704) \quad(-0.548412)$

(6. 634988) (-1.031753)

$\mathrm{R}^{2}=0.961003 \quad \mathrm{~F}=49.28601$

从模型的线性回归分析结果得知, 拟合优度 $\mathrm{R} 2$ 为 0.961 , 说明模型整体拟合得好; 当显著性水平 $a$ $=0.05$, 查表得临界值 $F(4,15)=3.06, F=49.28601$ 远大 于临界值, 进一步说明模型总体是显著。显著性水平 $a$ $=0.05$, 自由度 $\mathrm{n}-\mathrm{k}=16$ 的 $\mathrm{t}$ 统计量的临界值为 2.120 , 回 归结果 $\mathrm{X} 2 、 \mathrm{X} 4$ 的参数估计值 $\beta 2$ 和 $\beta 4$ 未通过参数的显 著性检验, 将不显著因子 $X 2 、 X 4$ 剔除做回归模型 $Y=\beta$ $0+\beta 1 X 1+\beta 3 X 3+\mu$, 得:

$$
\begin{array}{ccr}
\mathrm{Y}=27414.037414 & +1.018090 * \mathrm{X} 1+27.058852 * \mathrm{X} 3 \\
(15504.67) & (0.198753) & (3.391745) \\
\mathrm{t}=(0.768115) & (2.091021) & (7.977856)
\end{array}
$$

只有 $\mathrm{X} 1 、 \mathrm{X} 3$ 的参数的大小和符号符合经济意义, 通过经济意义的检验。变量 $\mathrm{X} 1 、 \mathrm{X} 3$ 对应的参数 $\beta 1$ 和 B 3 通过了参数的显著性检验。通过回归模型可以得 出: 在其它因素不变时, 农村居民人均可支配收入每增 长 1 元, 总体的保费收入预计会增加 27.05 万元; 同样 的在其它因素不变时, 财政保费补贴每增长 1 万元, 保 费收入预计会增加 1.01 万元。

\section{VI. 农业保险补贴存在的问题及建议}

\section{A. 存在的问题:}

近年来，由于实施了政策性的农业保险，我国农业 保险的发展迅速，保费收入逐年稳步增长，农覆盖区域 扩大，险种不断增加。但补贴政策也还存在着一些问 题:

（1）农业保险补贴的补偿率低，覆盖率低

补贴费用低、补贴资金不到位，覆盖率低等，如提 供的补偿大约只占到全国需要补贴的 $10 \%$ 左右。对偏远 贫困地区, 受地方财力不足的影响, 补贴不到位, 甚至 存在农业保险的补贴资金逾期到账现象。

（2）农业保险补贴制度不完善，存在市场违规现象

2007 年国家的保费补贴的政策之后，相关的法律、 规章制度还没有建立和完善, 逆向选择、道德风险时有 发生。农业保险补贴界定不明确导致理赔环节存在纠 纷, 农户的利益得不到保障, 造成农户对农业保险的信 任度下降。

（3）农业保险补贴的险种少，且补贴机制单一

目前农业保险提供补贴的险种主要是种植业、养殖 业，对特色农业种植险种的补贴少; 政府对农业保险的 补贴机制单一，没有差异化的补贴，导致一些地区的农 户投保积极性不高。

\section{B. 研究结论与建议}

从以上可以看出, 假设其他因素不变时, 财政保费 补贴对农业保险需求影响较小。而农村居民人均可支配 收入对农业保险需求影响最大, 说明, 农业保险市场的 发展主要依赖于农民的收入水平, 中央和地方对财政保 费补贴并没有起到预计的激励效果，与之前的分析的预 期不相符。虽然四川省的农村居民人均可支配收入逐年 增长, 从 1998 年的 1789 元增加到了 2018 年的 14617 元, 但是农民的收入整体来说还是不高, 再加上农业保 险的高费率，使得农民对农业保险的需求量不大。受成 
灾面积对农户对农业保险的需求影响不大，可能是近年 来农业灾害面积有所下降, 和在重特大自然灾害发生后 对政府和民间救济的依赖; 由于加大对种养殖业的激素 推广，农户自身的经验的积累，抵抗自然灾害的能力提 升，会选择其他规避自然灾害风险的方式。农业保险的 赔付率低, 要求严苛, 赔付水平不能弥补损失也使得农 户愿意购买农业保险, 甚至有些已经购买农业保险的农 户退保。

（1）增加农户收入;农民的收入是影响是否参保的最 重要的因素, 通过增加农民的收入将潜在的保险需求转 化为有效的保险需求

（2）加强农业保险政策宣传，改善农户参保意愿：农 业保险知识的普及包括险种、赔款条款、相关责任、赔 款原则等, 增加对农业保险的认知, 提高农户的参保意 识, 加强投保意愿。了解财政补贴政策认识到其补偿和 惠民作用。

（3）完善监督与管理机制，预防市场违规行为

保险公司要履行如实告知、最大诚信等原则, 确保 保单的真实有效性; 农户对农业保险条款了解, 防止其 逆向选择与道德风险行为, 预防骗保行为, 防止农户在 投保后从事更高风险的农业活动。

（4）创新农业保险补贴机制制定出符合各区域和不同 的风险的方法和措施, 保险公司根据实际尽可能地开发 出适应农民需求的险种, 以及在双方均可承受的范围内 设置合理的保费水平。同时鼓励农民扩大农业生产，激 励农民投保农业保险的积极性。对于农户自筹缴费的， 可以提供多渠道的筹资来源, 例如利用农业生产的补助 资金用于购买农业保险，或者利用理赔资金 “以险养 险”。

\section{参考文献}

[1] WRIGHT,HEWITT. Adverse selection, disaster relief, and the demand for multiple peril crop insurance. Washington DC:Contract Report for the FederalCrop Insurance Corporation,2006.

[2] JUSTIN. The demand for multiple perilcropinsurance:evidence from Montana wheat farmns.American Journal Agriculture Economics, 2010, 79(2):189-210

[3] RUSSELL. An expected indemnity approach to the measurement of moral hazard in crop insurance. American Journal AgricultureEconomics, 2014,79(2):216-226.
[4] DONOGHUE. A second look at subsidies andsupply. Lowa Agriculture Review 2014,6(1):3.

[5] COLLINS. Adverse selection in crop insurances sctuarial and asymmetric information incentives. American Journal Agriculture Economics,2006,81(4):838-849.

[6] TRONSTAD. Problems with market insurance in agriculture. American Journal Agriculture Economics2010 ,83(3):643-649.

[7] 于雪妍. 河南省农户农业保险投保意愿影响因素研究.河南农业大 学,2017.

[8] 沈昱池,夏慧琳.财政补贴对农业保险市场的影响初探——以盐城 为例.盐城工学院学报(社会科学版),2014,27(01):43-48.

[9] 刘晓丹.日本农业保险财政补贴机制研究.中国保险,2018(09):57-61

[10] 袁连升,范静,隋丽莉.财政补贴政策下农户购买农业保险行为实证 研究一一基于吉林省 200 多户农户的问卷调查.中国农机化学 报,2014,35(02):38-42

[11] 刘蔚,孙蓉.农险财政补贴影响农户行为及种植结构的传导机制一 一基于保费补贴前后全国面板数据比较分析. 保险研 究,2016(07):11-24

[12] 王根芳. 基于主体利益博交分析的农业保险补贴研究.华中农业大 学, 2013 .

[13] 姜岩,李扬.政府补贴、风险管理与农业保险参保行为一一基于江 苏省农户调查数据的实证分析.农业技术经济,2012(10):65-72.

[14] 王洪波.保费补贴对农业保险需求与供给的影响研究.科技与经 济,2016,29(04):41-45.

[15] 黄正军.我国农业保险财政补贴政策研究.广西社会科 学,2018(12):113-116.

[16] 夏益国,孙群,盛新新.以财政补贴校正农业保险市场失灵.经济纵 横,2015(05):75-78

[17] 刘桦灿,粟芳.农业保险保费补贴稳定农业保险经营的有效性检验. 上海金融,2018(10):23-31.

[18] 邓志英,黄毅,柳汝成.政策性农业保险补贴机制及效率研究一以湖 南省为例.宜春学院学报,2018,40(05):51-56.

[19] 刘璐,韩浩,马文杰.政府支农政策对农业保险需求的影响机制研究. 农业经济问题,2016,37(10):31-40+110.

[20] 李琴英.农户政策性农业保险需求意愿实证分析.河南社会科 学,2014,22(12):73-77+124.

[21] 胡义云.政府财政补贴对我国农业保险发展的影响分析.金融经 济,2016(12):24-26.

[22] 方伶俐. 中国农业保险需求与补贴问题研究. 华中农业大学,2008.

[23] 朱甜甜. 农业保险财政补贴效率评价研究. 安徽财经大学,2015. 